look like the so-called supplementary eyes along the belly and tail, the rare Macrurus sclerorhyncus, Hoplostethus Mediterraneus, and Haloporphyrus lepidion, from depths of $508,656,860$, and I 25 metres. We have at least two species of Terebratula from depths varying from 600 to I 200 metres. Several most interesting Crustaceans besides those mentioned, and even a non-swimming Brachyurous Decapod, from II25 metres! But what is still more interesting is the capture of several specimens of a Hyalonema, very probably $H$. Lusitanica, but without any spiral twist in its long spiculæ; we got them off the south and east coasts of Sardinia, in depths from 1600 to 623 metres; we have, besides, several other forms of Sponges, all siliceous, and several of a curious agaric-like form. We have a Brisinga from depths of 2145 to 2300 metres, but very few other Echinoderms; I do not yet give up the hope of seeing a Pentacrinus before our cruise is ended. We have, as I mentioned, various Annelids and Gephyreans, and some fine species of Madreporia of the deep-sea forms.

We have an interesting set of serial thermometric observations, which show that there is a slight difference in the bottom temperature between the basins east and west of Sardinia, the latter being slightly colder. Negretti and Zambra's new deep-sea thermometers have answered admirably, suspended in the peculiar frame devised by Capt. Magnaghi.

Naples, August 20

\section{ON THE VELOCITY OF LIGHT}

$\mathrm{THE}$ result announced by Young and Forbes (Roy. Soc. Proc., May I7, I881) that blue light travels in vacuo about 1.8 per cent. faster than red light, raises an interesting question as to what it is that is really determined by observations of this character. If the crest of an ordinary water wave were observed to travel at the rate of a foot per second, we should feel no hesitation in asserting that this was the velocity of the wave; and I suppose that in the ordinary language of undulationists the velocity of light means in the same way the velocity with which an individual wave travels. It is evident however that in the case of light, or even of sound, we have no means of identifying a particular wave so as to determine its rate of progress. What we really do in most cases is to impress some peculiarity, it may be of intensity, or of wave-length, or of polarisation, upon a part of an otherwise continuous train of waves, and determine the velocity at which this peculiarity travels. Thus in the experiments of Fizeau and Cornu, as well as in those of Young and Forbes, the light is rendered intermittent by the action of a toothed wheel; and the result is the velocity of the group of waves, and not necessarily the velocity of an individual wave. In a paper on Progressive Waves (Proc. Math. Soc. vol. ix.), reprinted as an appendix to vol. ii. of my book on the "Theory of Sound," I have investigated the general relation between the group-velocity $U$ and the wave-velocity $V$. It appears that if $k$ be inversely proportional to the wave-length,

$$
U=\frac{d(k V)}{d k}
$$

and is identical with $V$ only when $V$ is independent of $k$, as has hitherto been supposed to be the case for light in vacuum. If however, as Young and Forbes believe, $V$ varies with $k$, then $U$ and $V$ are different. The truth is however that these experiments tell us nothing in the first instance about the value of $V$. They relate to $U$; and if $V$ is to be deduced from them it must be by the aid of the above-given relation.

When we come to examine more closely the form of this relation, we see that a complete knowledge of $V$ (as a function $k$ ) leads to a complete knowledge of $U$, but that a complete knowledge of $U$-all that experiments of this kind can ever give us-does not determine $V$, without the aid of some auxiliary assumption. The usual assumption is that $V$ is independent of $k$, in which case $U$ is also independent of $k$. If we have reason to conclude from observation that $U$ is not independent of $k$, this assumption is disproved; but we can make no progress in determining $V$ until we have introduced some other.

It is not easy to see how the missing link is to be supplied; but in order to have an idea of the probable magnitude of the difference in question I have assumed the ordinary dispersion formula $V=A+B k^{2}$ to be applicable. Taking the ratio of wave-lengths of the orange-red and green-blue lights employed as $6: 5$, I find that for red light $V=U(1-0273)$, so that the velocity of the wave would be nearly 3 per cent. less than that given by Young and Forbes as the result of the experiment.

Under these circumstances it becomes a matter of interest to examine the bearing of other evidence on the question of the velocity of light. Independently of the method of the toothed wheel, the velocity of light has been determined by Foucault and Michelson using the revolving mirror. It is not very obvious at first sight whether the value thus arrived at is the group-velocity or the wave-velocity, but on examination it will be found 0 be the former. The successive wave-fronts of the light after the first reflection are not parallel, with the consequence that (unless $V$ be constant) an individual wave-front rotates in the air between the two reflections.

The evidence of the terrestrial methods relating exclusively to $U$, we turn to consider the astronomical methods. Of these there are two, depending respectively upon aberration and upon the eclipses of Jupiter's satellites. The latter evidently gives $U$. The former does not depend upon observing the propagation of a peculiarity impressed upon a train of waves, and therefore bas no relation to $U$. If we accept the usual theory of aberration as satisfactory, the result of a comparison between the coefficient found by observation and the solar parallax is $V$-the wave-velocity.

The question now arises whether the velocity found from aberration agrees with the results of the other methods. A comparison of the two astronomical determinations should give the ratio $U: V$, independently of the solar parallax. The following data are taken from Mr. Gill's "Determination of the Solar Parallax from observations of Mars made at the Island of Ascension in I877."

The time $k$, required by light to travel a mean radius of the earth's orbit, has been determined by two astronomers from the eclipses of Jupiter's satellites. Delambre found, from observations made in the last century, $k=493^{\circ} 2 \mathrm{~s}$., but recently Glasenapp has obtained from modern observations the considerably higher value, $k=500.8 \mathrm{~s} . \pm \mathrm{I} \cdot 02$. With regard to the constant of aberration, Bradley's value is $20^{\prime \prime} \cdot 25$, and Struve's value is $20^{\prime \prime} 445$. Mr. Gill calculates as the mean of the best modern determinations (nine in number), $2 \mathrm{O}^{\prime \prime} \cdot 496$.

If we combine Glasenapp's value of $k$ with Michelson's value of the velocity of light, we get for the solar parallax 8.76 . Struve's constant of aberration in conjunction with the same value of the velocity of light gives $8 " .8 \mathrm{r}$. From these statements it follows that if we regard the solar parallax as known, we get almost the same velocity of light from the eclipses of Jupiter's satellites as from aberration, although the first result relates to the group velocity, and the second to the wave velocity. If instead of Struve's value of the constant of aberration we take the mean above spoken of, we get for the solar parallax $8^{\prime \prime} \cdot 78$, allowing still less room for a difference between $U$ and $V$.

Again, we may obtain a comparison without the aid of the eclipses of Jupiter's satellites by introducing, as otherwise known, the value of the solar parallax. Mr. Gill's 
value from observations of Mars is $8^{\prime \prime} 78$, agreeing exactly with Michelson's light velocity and the mean constant of aberration. Some other astronomers favour a higher value of the solar parallax, such as $8^{\prime \prime} \cdot 86$; but whichever value we adopt, and whether we prefer Cornu's or Michelson's determination of the light velocity, the conclusion is that there can be no such difference between the group velocity and the wave velocity as 2 or 3 per cent., unless indeed the usual theory of aberration requires serious modification. These considerations appear to me to increase the already serious difficulties, which cause hesitation in accepting the views of Young and Forbes. The advent of further evidence will doubtless be watched with great interest by scientific men.

One other point I may refer to in conclusion. Speculations as to harmonic relations between various spectral rays emitted by a glowing gas proceed upon the assumption that the frequency of vibration is inversely proportional to the wave-length, or, in other words, that the velocity of propagation $V$ is independent of the wavelength, the question now at issue. If the views of Young and Forbes are correct, calculations of this kind must be overhauled. On the other hand, the establishment of well-defined simple ratios between wave-lengths would tend to show that $V$ does not vary.

RAYLEIGH

August 15

\section{ELECTRIC LIGHT IN COLLIERIES}

$\mathrm{A}^{\mathrm{u}}$

GUST 9, I88r, witnessed the first practical application in the United Kingdom of the electric light to the illuminating of coal-mines. The Earnock Colliery, near Hamilton, Lanarkshire, belonging to Mr. J. Watson, has been fitted with Swan's incandescent lamps specially arranged with outer lanterns of stout glass, air-tight, and provided with steel guards. The workings in which the lamps were fixed are 118 fathoms, or 708 feet below the surface. Twenty-one brilliant little lights placed at the pit-bottom, in the roads, and at the actual face of the seam where active operations were in process, supply an illumination of a very different character from the dismal glimmer of an occasional Davy. The electricity was generated by a dynamo-electric machine at the surface worked by a special i 2 horse-power engine, and conveyed by two cables, first along telegraph poles to the pit mouth, then down the shaft to the workings, in one section to a distance of half a mile. The overhead wires are naked copper wires of $\frac{3}{8}$ inch diameter, while those below ground are carefully insulated, and in the shaft are protected with an outer tube of galvanised iron. At suitable points of the circuit safety air-tight switches, the invention of Messrs. Graham of Glasgow, are inserted to afford control over individual lamps. The mine was visited two days after the installation of the light by members of the Mining Institute of Scotland, with whom was Mr. W. Galloway, whose remarkable experiments on the explosive effects of coal-dust will be remembered in connection with the more recent report of Prof. Abel. The party were photographed in the workings. An experiment was made with a lamp to test whether in the event of its being broken by accident a surrounding atmosphere of explosive gas would or would not be kindled by the strip of red-hot carbon before it had had time to cool. Into a box containing about three cubic feet of explosive gas a single lamp, removed from its outer protecting case of stout glass, was placed, and the current was turned on. The fragile bulb inclosing the incandescent carbon thread was then purposely broken, when the gas inclosed in the box immediately exploded. No such occurrence could possibly happen if the protecting case of stout glass is properly constructed. The risk of accident must be considered as immensely less than that of the ordinary Davy lamp, especially when it is remembered that with the brilliant light of the electric lamps they need no longer be carried in the hand or set down upon the floor near the actual spot where the coal is being got, but will be fixed overhead at a safe distance against the wall of the mine. The ease with which the light can be turned out during the firing of a blast is another point in their favour. The proprietor of the Earnock Colliery is greatly to be congratulated on the step he has taken. In 1880 the death-roll of the slain by explosions of fire-damp in Great Britain reached the figure of 499 persons. We venture to predict that the universal adoption of electric lighting in fiery mines would reduce this figure to one-tenth of its terrible proportions. How many years will it be, we wonder, before the adoption of electric lighting will be made compulsory by Act of Parliament? And how many colliery owners will discover, we would ask, when driven to this course by compulsion, that in the long run they effect an economy by discarding the clumsy and unsafe "safety"-lamp, which will so soon be numbered with the "flint mill" amongst the relics of the past?

\section{SINGULAR STONE HATCHETS ${ }^{\circ}$}

$\mathrm{M}$ ONSIEUR PITRE DE LISLE has lately called attention to a singular class of stone celts or hatchets which have for the most part, if not indeed only, been found in Brittany and North-Western France.

These hatchets, instead of tapering away to a more or less conical point at what has been termed the butt-end, suddenly expand close at that part, so as to present a somewhat button-like termination. In one instance, at least, the hatchet ends in a spheroidal ball not unlike that which one occasionally sees on the horns of cows which are inclined to make too free use of their natural arms of offence. In the case of the hatchets, however, the button is at the opposite end to that which was in use for cutting. These blades vary in length from about three inches to as much as fifteen inches, and are all made of rocks belonging to the family of Diorites, principally of Aphanite.

M. de Lisle has given to these instruments the name of "haches à tête" or "haches à bouton," and has pointed out the similarity which in some respects they bear to hatchets of Carib origin and to the merés of New Zealand. In these instances the object in view in forming a projecting rib round the end of the blade was no doubt to afford the means of preventing it from slipping out of the handle or hand which held it. He thinks that the same object led the makers of these French blades to adopt the same form, and that the hatchets, after passing through a transverse hole in their hafts, were secured by cords wound around them, which abutted against the projecting rims at their small end. In his opinion there is a representation of this method of hafting to be seen among the sculptures on the dolmen of Mané-Lud.

It is a remarkable circumstance that the hatchets of this particular form appear to be restricted to so small a district of France, and not to occur elsewhere. M. de Lisle is in consequence inclined to assign the development of this type to a late period in the Neolithic age, and has offered some reasons for inferring that in Brittany the use of bronze hardly found a home, and that stone was the principal material employed for cutting tools when first that part of Gaul was brought in contact with Roman civilisation. It seems probable enough that in that as in other countries there were districts which lay far away from the principal bighways of progress and civilisation, and where old-world usages prevailed long after material advances had been made in more fortunate but not very distant regions.

We may however be allowed to doubt whether the country of the Veneti, the most enterprising maritime tribe of Gaul, whose ships in the days of Julius Cæsar were already provided with chain-cables of iron, were I "Les Haches à Tête de la Pretagne, etc." (Nantes, 188o.) 